\title{
PERFORMANCE EVALUATION OF TAIWANESE INTERNATIONAL TOURIST HOTELS: EVIDENCE FROM A MODIFIED NDEA MODEL WITH ICA TECHNIQUE
}

\author{
Sheng-Hsiung CHIU ${ }^{1}$, Tzu-Yu LIN²* \\ ${ }^{1,2}$ Accounting School, Nanfang College of Sun Yat-Sen University, No. 882, Wenquan Road, \\ Wenquan Town, Conghua District, 510970, Guangzhou, The People's Republic of China
}

Received 12 July 2017; accepted 07 April 2018

\begin{abstract}
The motivation for this study is to assess the managerial performance in Taiwanese international tourist hotels based on the two-stage NDEA performance mechanism with ICA technique for enhancing the discriminatory power of performance evaluation model. The two-stage managerial performance structure is applied, incorporating the service production and service operation stages, as a reduced form to introduce the relatively complex business environment of modern enterprise. However, we have need to be considerable of dimensionality curse problem in NDEA performance model. A modified NDEA-based evaluation model, therefore, is proposed to integrate the network slacks-based measure (NSBM) with a dimensional reduction technique, the independent component analysis (ICA). The results indicate that the performance of the profit dimension significantly hampers operational performance, and that both regulators and managers must adjust their market orientation business strategy. Moreover, compared with the NSBM model, this modified ICA-NSBM performance model has a high discriminatory ability to measure the relative performance of the selected hotels.
\end{abstract}

Keywords: Taiwanese international tourist hotels, two-stage NDEA model, independent component analysis, network slacks-based measure, DEA, performance evaluation.

JEL Classification: D61, M21.

\section{Introduction}

The service sector has been the core of Taiwan's economy in the past decades, accounting for more than 60\% of Gross Domestic Product (GDP) and 59\% of labor force (NDC, 2016) in 2015. One of the prominent service industries is tourism, in which visitor expenditure almost account for 3\% of GDP in the same year. In light of the trend, promoting the development of tourism industry may as well be a good strategy for an island nation like Taiwan as a good driver for continuous growth of national economic, increasing employment

*Corresponding author. E-mail: blackmallows@gmail.com

This is an Open Access article distributed under the terms of the Creative Commons Attribution License (http://creativecommons. org/licenses/by/4.0/), which permits unrestricted use, distribution, and reproduction in any medium, provided the original author and source are credited. 
and foreign exchange reserve. The main theme of Taiwan tourism is "Taiwan - The Heart of Asia" suggesting that Taiwan can provide abundant travel experience as the key hub in Asian tourism. Meanwhile, the slogan: “Time for Taiwan” is used to call for real actions on international travelers. These marketing strategies have deepened Taiwan's brand-name impression, which has also translated into 14.7 billion US Dollars of tourism revenue in 2013. In 2008, Taiwan opened up its local tourism market to tourists from mainland China, expecting to see additional growth momentum of the tourism industry. According to the statistics from Taiwan Tourism Bureau, the annually growth rate of Chinese tourists was significantly higher than that of the total visitor arrivals during 2008 to 2015 . There has been a $10 \%$ drop in the number of visitor arrival from China since 2016, due to complicated political circumstances between Taiwan and Mainland China. Nevertheless, the fact that tourists from other countries has peaked at the same time, has also helped to close the gap.

The hotel industry has played a key role in the development of Taiwanese tourism to satisfy the need of the increasing number of domestic and foreign recreational travelers, by creating economic benefits through accommodations, meals and all other services. As tourism booms in Taiwan, increase in investment, such as new constructions and/or upgrade of buildings, has also accelerated competitions in the Taiwanese hotel industry. Between 2009 and 2012, as shown in Table 1, there are thirteen newly built international tourist hotels entering the business, reinforcing the market competition. In light of this trend, both the government and managers of hotels shall act more progressively to strengthen industrial and/ or corporate competitiveness. Thus, the two priorities: the efficiency and the effectiveness of service production and service operation, become even more important under the performance-based management framework for the hotel industry; accurate performance evaluation has become the focus for even greater attention for both hotel owner and governmental policymakers, since it can provide valuable managerial information regarding where the competitive edge is for marketing management, and contribute to the strategic plans and to the upgrade of service quality (Hwang \& Chang, 2003; Hadad, Friedman, \& Israeli, 2005; Chen, 2009; Hu, Chiu, Shieh, \& Huang, 2010; Assaf \& Barros, 2011; Huang, Ho, \& Chiu, 2014; Ban, Tara, Bogdan, Tuşe, \& Bologa, 2016; Oukil, Channouf, \& AL-Zaidi, 2016; Huang, 2018).

Data envelopment analysis (DEA) is a well-known performance evaluation model, which has been devoted to various industry for measuring the relative performance, including the tourism industry. There are number of studies have proposed performance evaluation approaches for the tourism industry using uni- dimensional (Hwang \& Chang, 2003; Yang, Xia, \& Cheng, 2017) and multi-dimensional models (Yu \& Lee, 2009; Hsieh \& Lin, 2010; Huang et al., 2014). Färe and Grosskopf (2000) proposed an innovative approach of the DEA methodology, namely network DEA (NDEA), which can be adopted to decompose the individual components of organizational performance. This division of organizational performance offers many practical applications, notably providing valuable performance data to management in a more efficient manner (Färe \& Grosskopf, 2000; Vaz, Camanho, \& Guimarães, 2010). The NDEA methodologies used in previous studies can be divided into two groups: radial models and non-radial models. While radial models assume that input reductions and output expansions change proportionally (Seiford \& Zhu, 1999; Lewis \& Sexton, 2004; 
Castelli, Pesenti, \& Ukovich, 2010; Yang \& Liu, 2012; Kao, Wu, \& Huang, 2017; Marchetti $\&$ Wanke, 2017), non-radial models are a more flexible evaluation tool that can compute input contractions and output improvements individually (Yu \& Lin, 2008; Barros, Managi, \& Matousek, 2012; Xu \& Cui, 2017). Furthermore, given that slacks have been recognized as important factors in explaining inefficient behavior (Mahlberg \& Sahoo, 2011), a network slacks-based measure (NSBM) model proposed by Tone and Tsutsui (2009) has been widely used for performance evaluation in various industries (Avkiran, 2009; Yu, 2010; Galagedera, Watson, Premachandra, \& Chen, 2016; Zha, Liang, Wu, \& Bian, 2016; Xu \& Cui, 2017).

While we want to improve the discriminatory ability of the DEA-based performance model by expanding the dimensionality, higher dimensionality by using two or over-stage performance structure, it may still cause bias in the performance evaluation due to strong correlation among variables. The task, then, is to distinguish efficient units from inefficient ones more accurately, especially in the presence of a set of high-dimensional variables (Jenkins \& Anderson, 2003). There are several empirical evidences from previous studies to show that the combination of DEA model with dimensional reduction technique is an effective way to improve the discriminatory power of its (Adler \& Golany, 2001, 2002; Liang, Y. Li, \& S. Li, 2009; Adler \& Yazhemsky, 2010; Kao, Lu, \& Chiu, 2011; Lin \& Chiu, 2013). For example, Bian (2012) obtained Schmidt variables to replace the original outputs via a Gram-Schmidt process, while Nataraja and Johnson (2011) presented a principal component analysis (PCA)DEA model that had highly correlated input variables for a small data set. Kao et al. (2011) further extended the independent component analysis (ICA) approach for selecting necessary input variables, which were then fed into the conventional DEA model, to evaluate the performance of Taiwanese medical industry. The integration of ICA and DEA-based models has also been applied to the medical service industry (Kao et al., 2011; Afsharinia, Bagherpour, \& Farahmand, 2013) and the banking industry (Lin \& Chiu, 2013). It has been demonstrated that an appropriate dimension reduction approach is necessary to the DEAbased performance model, to avoid evaluation bias. There have been a handful of studies focusing on the operating performance of Taiwanese international tourist hotels, however, discussion on the enhancement of DEA-based performance model's discriminatory power remains relatively scarce.

To enrich the literatures, we proposed a modified ICA-NSBM performance model, which underlines the model's discriminatory ability, while at the same time make full use of the information under the multi-stage frame, to evaluate the managerial performance of Taiwanese international tourist hotels during the period 2009 to 2015 . We started with the commonly used two-stage NDEA-based evaluation model to develop a proper evaluation framework. As the managerial performance of international tourist hotels in Taiwan can be decomposed into the service production stage and service operation stage, we chose appropriate variables of each stages as suggested by Yu and Lee (2009) and Huang et al. (2014). We then used the ICA technique to address the dimensionality issue, which may affect the DEA-based performance model's discriminatory ability (Kao et al., 2011; Lin \& Chiu, 2013), by generating independent components (ICs) under the assumption of statistical independence among previously selected variables for input, intermediate input/output, and output. We postulated that the dimension-reduced and modified form of two-stage NDEA-based performance model, 
namely ICA-NSBM, had improved discriminatory ability for performance evaluation. The contributions of this study are twofold. First, we enhance the discriminatory ability of the DEA-based performance model by applying ICA technique to the extended two-stage NDEA performance model, allowing better measurement of managerial performance of Taiwanese international tourist. Second, as lack of long-term performance evaluation of Taiwanese international tourist hotels leaves government and manager uncertain as to whether the managerial performance of Taiwanese international tourist hotel has improved under specific policy, using the modified ICA-NSBM model, we can measure and rank accordingly the managerial performance of Taiwanese international tourist hotels more accurately during the period 2009-2015. The results could be useful to assess the impact of tourism policies and marketing strategies on Taiwanese international tourist hotels. In addition, our model can also help to reveal stage-level inefficiency for hotel managers.

The remainder of this paper is structured as follows. Section 1 introduces the proposed performance measures, variables selection, and the sample data for our empirical work. Section 2 highlights the proposed ICA-NSBM model. Section 3 discusses the empirical results. Finally, a summary of the main findings and concluding remarks are presented.

\section{Performance evaluation framework and sample data}

\subsection{Two-stage performance model}

Tourism is viewed as the fastest growing industry of Taiwan in terms of its economic value added creation ability. According to the tourism statistics of Taiwan Tourism Bureau (2017), business and leisure are the two main propose of visitors who arrived in Taiwan. There are more than $25 \%$ of visitors who stayed for 5 to 7 nights and the average length of stay of visitors is approximately 6.3 nights in 2017. As the continuing growth of foreign visitors and oversea Chinese, there may be an opportunity for the Taiwanese international tourists' benefit but the business operation may also be suffered from a severe competition when the international tourist hotel industry has a lot of foreign and domestic participators. An accurate performance model with better discriminatory power can be an important managerial tool by providing an inefficient information for managerial decision-making. In the Taiwanese hotel industry, hotels' operations can be divided into two main service processes, namely accommodation and dining facilities, which constitute approximately $80 \%$ of total revenue. In other words, from an input-output perspective to demonstrate the managerial performance of hotel industry, hotels invest heavily in capital and labor, more so in human resources, in order to provide accommodation, dining facilities, and other services to entice potential customers for the primary objective as service operation in mind.

The efficiency and effectiveness of the accommodation and dining services capacity provided are thus crucial to further marketing, operating, and profit creation potential of the business model. Based on the proposed performance evaluation model from $\mathrm{Yu}$ and Lee (2009) and Huang et al. (2014), the two-stage performance evaluation framework of hotels' operation is also applied in this paper, namely service production and service operation stages, as shown in Figure 1. This decomposition approach can be used to comprehensively 


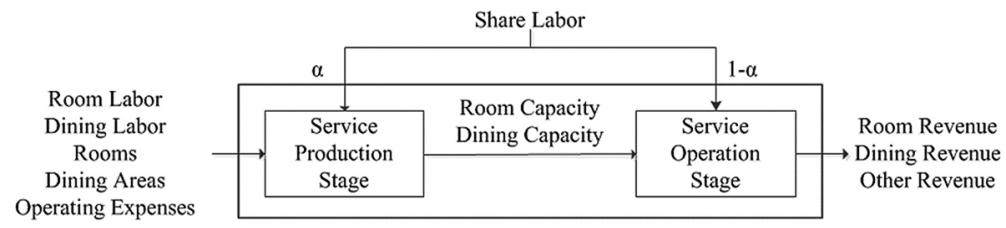

Figure 1. The two-stage managerial performance framework of international tourist hotels in Taiwan

evaluate the managerial performance of Taiwanese international tourist hotels and to identify the main sources of inefficiency for suggesting possible improvements. We select input, intermediate, and output variables to evaluate the managerial performances of Taiwanese hotels following Yu and Lee (2009) and Huang et al. (2014), as depicted in Figure 1. Three outputs are selected to evaluate the performance of service operation stage: (1) room revenue: the revenue generated from the accommodation service; (2) dining revenue: the revenue generated from the dining service; and (3) other revenue: the revenue generated from other services. Meanwhile, the following five input variables are chosen on service production stage: (1) room labor: the number of full-time employees working in the accommodation service; (2) dining labor: the number of full-time employees working in the dining service; (3) rooms: the number of rooms; (4) dining areas: the total floor area of the dining service; and (5) expenses: operating expenses excluding salaries. In addition, one shared input (i.e., shared labor: number of employees in the managerial department that are responsible for administering both the accommodation and the dining services) can be further separated into the service production and service operation stages. Two intermediate variables, (1) room capacity: the total number of rooms available for rent annually, which is dividend by the number of rooms occupied by the room occupancy rate and (2) dining capacity: the total capacity of dinner service annually is measured by multiplying the floor area of dinning service by the number of employer of dinner service, are selected to be an intermediate output from the service production stage. One of the unique character of service industry is that the service cannot be stored. We do not know whether it is efficient to use these inputs to cover into room and dining services capacity available annually. The outputs from the service production stage as the inputs of the next stage, which are interconnected between the service production and service operation stages. Revenue creation of service capacity is also an important issue for evaluating the managerial performance. In addition, we assume that an international hotel utilizes a proportion $\alpha$ of shared labor (e.g., managerial labor) for the service production stage and $(1-\alpha)$ for the service operation stage. For simplicity, we also assume the value of $\alpha$ to be 0.5 for each stage.

\subsection{Data collection}

The mainland Chinese people coming to Taiwan for tourism has been permitted by Taiwan government in 2008 for the purpose of attracting more oversea tourists to boom the tourism industrial development. The main purpose of this paper is to measure the managerial performance of Taiwanese international tourist hotels and find out who is the best hotel performer 
after the aggressive tourism policy that has brought the international tourist hotels having the advantage of income creation. Table 1 reports the number of Taiwanese international tourist hotels and the categorical type by region defined from Tourism Bureau of Taiwan. It is noticed that there are 13 newly international tourist hotels operated between 2010 and 2012. A pooled dataset is, therefore, used in this paper, incorporating hotels who belong to the category of international tourist hotels and operate in Taiwan over the period 2009-2015. The operational information of each selected hotels has been obtained from Annual Report on Tourist Hotel Operations in Taiwan published by the Tourism Bureau of Taiwan. Overall, there are 470 international tourist hotel observations in our initial sample base, but only 1 international tourist hotel, which did not have the necessary information of the selected variables in 2014, was excluded. The final sample data set thus has a total amount of 469 hotels and the descriptive statistics is summarized in Table 2.

Table 1. The number and regional location of operating Taiwanese international tourist hotels

\begin{tabular}{|l|c|c|c|c|c|c|c|}
\hline Regional Location & 2009 & 2010 & 2011 & 2012 & 2013 & 2014 & 2015 \\
\hline Taipei & 21 & 22 & 23 & 24 & 24 & 23 & 24 \\
\hline Kaohsiung & 7 & 8 & 8 & 8 & 8 & 8 & 8 \\
\hline Taichung & 5 & 5 & 5 & 5 & 5 & 5 & 5 \\
\hline Hualien & 5 & 5 & 5 & 5 & 5 & 5 & 5 \\
\hline Scenic & 9 & 10 & 11 & 11 & 11 & 11 & 11 \\
\hline TauHsiuMiao & 4 & 6 & 7 & 7 & 7 & 7 & 7 \\
\hline Other & 6 & 7 & 9 & 10 & 10 & 11 & 11 \\
\hline Total & 57 & 63 & 68 & 70 & 70 & 70 & 71 \\
\hline
\end{tabular}

Table 2. Descriptive statistics of Taiwanese international tourist hotels

\begin{tabular}{|c|c|c|c|c|c|c|c|c|c|}
\hline Stage & Variables & Year & 2009 & 2010 & 2011 & 2012 & 2013 & 2014 & 2015 \\
\hline \multirow{10}{*}{ 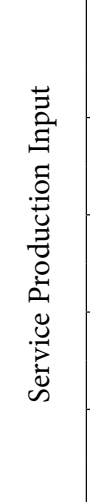 } & \multirow{2}{*}{$\begin{array}{l}\text { Room } \\
\text { Labor }\end{array}$} & Mean & 88.30 & 86.51 & 89.19 & 89.83 & 92.14 & 88.64 & 89.94 \\
\hline & & S.D. & 53.35 & 53.61 & 53.95 & 52.80 & 55.11 & 52.37 & 53.94 \\
\hline & \multirow{2}{*}{$\begin{array}{l}\text { Dining } \\
\text { Labor }\end{array}$} & Mean & 138.95 & 136.67 & 139.53 & 144.41 & 147.80 & 142.50 & 147.63 \\
\hline & & S.D. & 110.95 & 112.96 & 112.22 & 114.39 & 116.54 & 113.91 & 117.69 \\
\hline & \multirow{2}{*}{ Rooms } & Mean & 300.14 & 291.57 & 290.87 & 290.73 & 290.94 & 287.97 & 288.86 \\
\hline & & S.D. & 149.68 & 146.04 & 151.24 & 150.09 & 150.04 & 152.44 & 153.80 \\
\hline & \multirow{2}{*}{$\begin{array}{l}\text { Dining } \\
\text { Areas }\end{array}$} & Mean & $4,583.70$ & $4,237.16$ & $4,135.06$ & $3,876.43$ & $3,876.43$ & $3,439.76$ & $3,421.31$ \\
\hline & & S.D. & $7,133.11$ & $6,790.71$ & $6,569.74$ & $4,398.79$ & $4,398.79$ & $2,713.63$ & $2,708.41$ \\
\hline & \multirow{2}{*}{$\begin{array}{l}\text { Operating } \\
\text { Expenses }\end{array}$} & Mean & 344.54 & 351.21 & 383.29 & 402.83 & 417.91 & 412.29 & 422.93 \\
\hline & & S.D. & 320.56 & 331.98 & 337.25 & 362.26 & 381.98 & 375.58 & 386.99 \\
\hline \multirow{2}{*}{ 売 } & \multirow{2}{*}{$\begin{array}{l}\text { Managerial } \\
\text { Labor }\end{array}$} & Mean & 24.47 & 23.87 & 23.46 & 24.07 & 24.07 & 24.73 & 23.93 \\
\hline & & S.D. & 19.84 & 18.94 & 18.21 & 19.73 & 19.18 & 23.29 & 22.50 \\
\hline
\end{tabular}


End of Table 2

\begin{tabular}{|c|c|c|c|c|c|c|c|c|c|}
\hline Stage & Variables & Year & 2009 & 2010 & 2011 & 2012 & 2013 & 2014 & 2015 \\
\hline \multirow{4}{*}{ 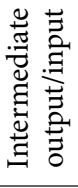 } & \multirow{2}{*}{$\begin{array}{l}\text { Room } \\
\text { Capacity }\end{array}$} & ean & 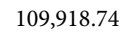 & 88 & 66 & 14 & 105,1 & 104,4 & 5.93 \\
\hline & & S.D. & 55,17 & $53,801.61$ & $55,440.48$ & $52,651.21$ & $50,454.74$ & $53,236.96$ & $55,760.40$ \\
\hline & \multirow{2}{*}{$\begin{array}{l}\text { Dining } \\
\text { Capacity }\end{array}$} & Mean & $990,657.44$ & $914,335.63$ & $873,896.66$ & $810,737.43$ & $820,864.16$ & $656,909.10$ & $669,954.31$ \\
\hline & & S.D. & $, 455,306.24$ & $2,411,246.68$ & $2,330,652.84$ & $1,650,358.57$ & $1,652,183.52$ & $947,566.26$ & $958,872.53$ \\
\hline \multirow{6}{*}{ 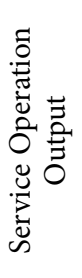 } & \multirow{2}{*}{$\begin{array}{l}\text { Room } \\
\text { Revenue }\end{array}$} & Mean & 22307 & 23394 & 251.82 & 269.57 & 283.69 & 286.51 & 298.24 \\
\hline & & S.D. & 10 & 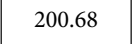 & 20614 & 227 & 234.13 & 226.24 & 255.26 \\
\hline & \multirow{2}{*}{$\begin{array}{l}\text { Dining } \\
\text { Revenue }\end{array}$} & Mean & 247.01 & 271.57 & 293.57 & 288.44 & 301.81 & 304.44 & 314.35 \\
\hline & & S.D. & 255.99 & 295.05 & 296.23 & 289.38 & 306.15 & 310.04 & 317.71 \\
\hline & \multirow{2}{*}{$\begin{array}{l}\text { Other } \\
\text { Revenue }\end{array}$} & Mean & 22 & 74.05 & 76.51 & 86.51 & 85.40 & 88.21 & 86.83 \\
\hline & & S.D. & 65.10 & 101.58 & 106.25 & 136.55 & 134.29 & 139.15 & 141.81 \\
\hline
\end{tabular}

Note: value of operating expense, room revenue, dinning revenue, and other revenue are million NT dollars.

\section{Methodology}

The main objective of this study is to measure the relative managerial performance of Taiwanese international tourist hotels, using the proposed ICA-NSBM model. To start, the managerial operation of Taiwanese international tourist hotel is simplified into two service stages with intermediate linkage, namely the service production stage and the service operation stage, in the sequential form illustrated in Figure 1. This way, we can properly adopt the NSBM model proposed by Tone and Tsutsui (2009), which successfully extend DEA-based performance model to consider the effect of intermediate variable between two consecutive stages/processes in the unified mathematical evaluation process, as the fundamental frame of the two-stage NDEA performance evaluation in this study. It is worth mentioning that, in the case of international tourist hotels in Taiwan, the accommodation and dining services are two mainly profitable service categories throughout the service production and operation stages. Because there are mass variables identified and selected from previous literatures to interpret the hotel's operation in a managerial vision, there is potential strongly correlation among selected variables, which may cause biased performance evaluations from the NSBM model. We adopted the independent component (IC) analysis introduced by Hyvärinen and Oja (2000) to address the evaluation bias issue, and to enhance the discriminatory ability of the extended NSBM model. By selecting variables consistent with the statistical independence assumption, we were able to construct a modified ICA-NSBM model to estimate the managerial performance of international tourist hotels in Taiwan. The following paragraphs detailed the model construction process.

\subsection{ICA approach}

The ICA is a useful variable selection method that could be seen as an extension of PCA. It aims to transform observed variables into ICs in terms of a linear combination of underlying latent variables. We introduce the basic ICA model proposed by Hyvärinen and Oja (2000) 
to reduce the dimensionality of the presented variables. For the basic ICA model, we assume that $m$ observed variables indicated by $x_{i}, i=1,2, \ldots, m$ could be represented as a linear combination of $n$ unknown ICs with non-Gaussian characteristics, $s_{j}, j=1,2, \ldots, n$. Given these assumptions, the observed variables matrix $X$ can be written as follows (Hyvärinen, Karhunen, \& Oja, 2001):

$$
X=A S=\sum_{i=1}^{m} \sum_{j=1}^{n} \alpha_{i j} s_{j},
$$

where $A$ is an unknown mixing matrix, $A$ is a statistically independent latent variables matrix that cannot be directly measured from the observed variables matrix $X$, and $\alpha_{i j}$ represents the effect of $s_{j}$ on $x_{i}$. The objective of the ICA model is to find the unknown mixing matrix $A$ according to a de-mixing matrix $W$ for estimating the IC matrix $A$. Substituting the estimated $W$ for $A$, the equation can be rewritten as:

$$
Y=S=W X=A^{-1} X,
$$

where $Y$ is the estimated IC matrix to be close to $S$.

Clearly, the de-mixing matrix $W$ is applied to transform the observed matrix $X$ in order to generate the corresponding ICs such that the vectors of $Y$ must be estimated to be as statistically independent as possible; these ICs are then used to estimate and represent the latent variable $s_{j}$.

After estimating the ICs, choosing appropriate ICs is more important for further DEAbased performance evaluation because of variable dependence. In contrast to PCA, the ICA approach does not stress the importance of estimated ICs with respect to the order. We follow Back and Weigend (1997) and García-Ferrer, González-Prieto, and Peña (2012), who proposed the concept of the maximum variance explained, to select the appropriate ICs. According to equation (1), the variance of the observed variables, $X$, is represented as follows:

$$
\operatorname{var}(X)=\sum_{j=1}^{m} \alpha_{i j}^{2}, \quad i=1,2, \ldots, m .
$$

For each $x_{i}$, the $j$ th-weighted ICs are given by $s_{j}^{w}=\alpha_{i j} s_{j}$, for $j=1,2, \ldots, m$, and their variances are stated below (Back \& Weigend, 1997; García-Ferrer et al., 2012):

$$
\operatorname{var}\left(s_{j}^{w}\right)=\alpha_{i j}^{2}, \quad i, j=1,2, \ldots, m .
$$

The variance of $x_{i}$, therefore, which can be explained by $s_{j}^{w}$, is computed in terms of equations (3) and (4) as follows (Back \& Weigend, 1997; García-Ferrer et al., 2012):

$$
v_{j}^{i}=\frac{\alpha_{i j}^{2}}{\sum_{j=1}^{m} \alpha_{i j}^{2}}, i, j=1,2, \ldots, m .
$$

Moreover, the total variance of $X$ explained by the $j$ th IC is given as follows:

$$
\partial_{j}=\frac{\sum_{j=1}^{m} v_{j}^{i}}{\sum_{i=1}^{m}\left(\sum_{j=1}^{m} v_{j}^{i}\right)}, j=1,2, \ldots, m .
$$


From equation (6), we can obtain the variance explained of the observed variables from each IC. Thus, the most important IC is that which explains the maximum variance of the observed variables.

\subsection{NSBM model}

Tone and Tsutsui (2009) proposed the NSBM model to deal with intermediate measures directly in a single evaluation procedure by introducing the concept of slacks in the objective function in order to measure the efficiency score.

In the NSBM model, suppose there are $n$ DMUs (Taiwanese international hotels) $(j=1$, $2, \ldots, n)$ that consist of $K$ stages $(k=1,2, \ldots, K)$. Let $m_{k}$ and $r_{k}$ be the numbers of inputs and outputs to stage $k$, respectively. In addition, the authors denoted the intermediate link leading from stage $k$ to stage $h$ by $z^{(k, h)}$ and the input (output) slacks to stage $k$ by $s^{k-}\left(s^{k+}\right)$. Thus, the objective function of the evaluation of managerial performance for the international hotel sector, $\rho^{N S B M}$, is defined as follows:

Subject to:

$$
\rho^{N S B M}=\min \frac{\sum_{k=1}^{K} w^{k}\left[1-\frac{1}{m_{k}}\left(\sum_{i=1}^{m_{k}} \frac{s^{k-}}{x_{i o}^{k}}\right)\right]}{\sum_{k=1}^{K} w^{k}\left[1+\frac{1}{r_{k}}\left(\sum_{r=1}^{r_{k}} \frac{s^{k+}}{y_{r o}^{k}}\right)\right]} .
$$

$$
\begin{aligned}
& \sum_{j=1}^{n} \lambda^{P E} X^{P E}=X^{P E}-S^{P E-} ; \\
& \sum_{j=1}^{n} \lambda^{P E} Z^{(P E, O E V)}=\sum_{j=1}^{n} \lambda^{P E V} Z^{(P E, O E V)} \\
& \sum_{j=1}^{n} \lambda^{P E}=1 ; \lambda^{P E}, S^{P E-} \geq 0 ; \\
& \sum_{j=1}^{n} \lambda^{O E V} Y^{O E V}=Y^{O E V}+S^{O E V+} ; \\
& \sum_{j=1}^{n} \lambda^{O E V}=1 ; \lambda O E V, S^{O E V+} \geq 0 ; \\
& w^{P E}+w^{O E V}=1, w^{k} \geq 0,
\end{aligned}
$$

where the superscripts refer to the stages $P E$ and $O E V$ that symbolize the service production and service operation stages, respectively, and $(P E, O E V)$ indicates the intermediate output, $P E$, from the service production stage converting into the service operation stage, $O E V$. With regard to the free linking constraints (7.2) imposed on this model, we needed to assume that the output of the previous stage was the same as the input of the following stage. Moreover, because $w^{k}$ is a user-specified weight for each stage, we can observe the specific contribution to the operational performance of each international hotel. Since a separate value of $w^{k}$ is subjective for each hotel management, we also restrict the value of $w^{k}$ to be 0.5 for each stage. 
In addition to operational performance, Tone and Tsutsui (2009) also defined the objective function of efficiency for each stage as follows:

$$
\rho_{k}^{N S B M}=\frac{1-\frac{1}{m_{k}}\left(\sum_{i=1}^{m_{k}} \frac{s^{k-*}}{x_{i o}^{k}}\right)}{1+\frac{1}{r_{k}}\left(\sum_{r=1}^{r_{k}} \frac{s^{k+^{*}}}{y_{r o}^{k}}\right)},
$$

where $s^{k-^{*}}$ and $s^{k+*}$ represent the optimal input and output slacks for equation (7).

Finally, we used the NSBM model to measure the managerial performance at the hotel level as well as to estimate the efficiency of the two stage $s$ in order to provide specific managerial insights into the sources of inefficiency.

\section{Empirical results and discussion}

\subsection{Efficiency analysis using the ICA-NSBM model}

Bian (2012) pointed out that evaluating performance using the DEA methodology is inferior in differentiation, given the large dimensionality of the database, in which there exist multiple correlations among the original inputs/outputs. Kao et al. (2011) stated that if the inputs of observed DMUs are strongly correlated, the evaluation outcome of DEA model will deviate. They thus introduced the ICA approach in order to choose a subset of variables that provides the majority of information contained within the original variables before conducting DEA. As discussed above, from the correlation matrix of the obtained variables shown in Table 3 , high and positive values of the correlation coefficients are observed for the input, intermediate, and output variables that are selected to construct NDEA based evaluation framework. This indicates the presence of high dimensionality in the data set may influence the performance evaluation results of the two-stage NDEA model proposed in this study. The ICA approach was then introduced to address the issue. In comparison with Kao et al. (2011), however, we not only dealt with the input variables, but also extended our analysis to cover intermediate and output variables under the NSBM model for evaluating hotel performance. With empirical analysis using data from international tourist hotel industry in Taiwan, we then postulated that the ICA-NSBM model was more efficient in managerial performance evaluation.

In the ICA approach, we estimated a de-mixing matrix $\mathrm{W}$ to obtain independent components with statistical independence based on the original variable set. We used the ICA approach to find six ICs (ICP1 ICP6) for service production inputs, two ICs (ICI1 ICI2) for intermediate outputs/inputs, and three ICs (ICO1 ICO3) based on the number of original variables. From the IC with the higher percentage of variance explained of the original data structure, the most meaningful IC can be identified (García-Ferrer et al., 2012), and then it will be treated as a new input, intermediate, or output variable that subsequently fed into the NSBM model for measuring the managerial performance score. The question of how many ICs should be selected into the new variable set remains open to interpretation and 
is of further research interest. In this study, we elected to keep ICs with highest percentage of variance such that the proportion of the total variance explained by selected ICs were accumulatively close to at least $80 \%$. The selection results in Table 4 demonstrated the cumulative variability explained by the number of selected ICs. In 2015, for example, we found that ICP3, ICP2, and ICP4 can explain $52.18 \%, 23.12 \%$, and $10.65 \%$ of the data variation, respectively, which accumulatively accounted for $85.95 \%$ of variation explanation, hence we selected these three ICs in replace of the original input variables. With the same token, ICI1 and IC12 were selected as the intermediate inputs/outputs, and ICO2 and ICO3 are selected as the outputs in the service operation stage.

Consequently, the indices for managerial performance, service production efficiency, and service operation effectiveness of international tourist hotels in Taiwan over the period 2009-2015, were calculated from the proposed ICA-NSBM model. Table 5 demonstrated the ranking results of the proposed ICA-NSBM model based on the average score of their managerial performance, showing the top 10 hotels that performed best and the bottom 10 ones, in the managerial performance evaluation. The results could be further decomposed into service production efficiency and service operation effectiveness. The managerial performance of each international tourist hotel could be ranked consistently and annually from 2009 to 2015. Since the managerial performance of international tourist hotels in Taiwan were mainly affected by the performance in the service production and service operation stages, uncovering the inefficiency sources in these two stages, then, could be insightful to understand the rank changes of the managerial performance from year to year. For instance, we observed that DMU28 and DMU51 were the top performers over the period 2009-2015. Moreover, DMU28 had been the top performer in both the service production and the service operation stages. The result is not surprising, as DMU28 was located in Kaohsiung area, a major city in southern Taiwan, and its dominance could be attributed to the high market share in terms of service revenue. In addition, we observed that DMU17 was ranked the Top 6 over the research period based on the managerial performance. It was ranked top 1 before 2012, and then dropped to between 7 and 40 afterwards. The falling could be attributed to the volatility of service operation effectiveness. Keep in mind that for international tourist hotel industry in Taiwan, its ability of revenue creation is not in accord with the total number of rooms and the total floor area of dinning service. In other words, there were still a good amount of unused capacity to be exploited. Finally, we found that the performance behavior in the service operation stage is the key to enhance the managerial performance of international tourist hotels in Taiwan, while they generally performed well in the service production stage (average score is approximately 0.9 and the standard deviation is 0.1 ), However, their revenue creation ability seemed unable to take advantage of economy of scale in the service production stage. 
Table 3. The correlation matrix of variables set

\begin{tabular}{|l|c|c|c|c|c|c|c|c|c|c|c|}
\hline & RL & DL & RS & DA & EXP & SL & RC & DC & R.REV & D.REV & O.REV \\
\hline RL & 1 & & & & & & & & & & \\
\hline DL & $0.826^{* *}$ & 1 & & & & & & & & & \\
\hline RS & $0.865^{* *}$ & $0.794^{* *}$ & 1 & & & & & & & & \\
\hline DA & $0.796^{* *}$ & $0.773^{* *}$ & $0.697^{* *}$ & 1 & & & & & & & \\
\hline EXP & $0.502^{* *}$ & $0.541^{* *}$ & $0.524^{* *}$ & $0.665^{* *}$ & 1 & & & & & & \\
\hline SL & $0.831^{* *}$ & $0.896^{* *}$ & $0.877^{* *}$ & $0.695^{* *}$ & $0.583^{* *}$ & 1 & & & & & \\
\hline RC & $0.730^{* *}$ & $0.769^{* *}$ & $0.753^{* *}$ & $0.678^{* *}$ & $0.542^{* *}$ & $0.797^{* *}$ & 1 & & & & \\
\hline DC & $0.813^{* *}$ & $0.756^{* *}$ & $0.706^{* *}$ & $0.991^{* *}$ & $0.618^{* *}$ & $0.689^{* *}$ & $0.652^{* *}$ & 1 & & & \\
\hline R.REV & $0.619^{* *}$ & $0.689^{* *}$ & $0.692^{* *}$ & $0.723^{* *}$ & $0.920^{* *}$ & $0.734^{* *}$ & $0.659^{* *}$ & $0.675^{* *}$ & 1 & & \\
\hline D.REV & $0.827^{* *}$ & $0.834^{* *}$ & $0.955^{* *}$ & $0.677^{* *}$ & $0.545^{* *}$ & $0.911^{* *}$ & $0.778^{* *}$ & $0.673^{* *}$ & $0.727^{* *}$ & 1 & \\
\hline O.REV & $0.750^{* *}$ & $0.609^{* *}$ & $0.714^{* *}$ & $0.478^{* *}$ & $0.397^{* *}$ & $0.724^{* *}$ & $0.615^{* *}$ & $0.473^{* *}$ & $0.546^{* *}$ & $0.750^{* *}$ & 1 \\
\hline
\end{tabular}

Note: RL (room labor): the number of full-time employees working in the accommodation service; DL (dining labor): the number of full-time employees working in the dining service; RS (rooms): the number of rooms; DA (dining areas): the total floor area of the dining service number of rooms; EXP (expenses): operating expenses excluding salaries; RC (room capacity): the total number of rooms available for rent per year; DC(dining capacity): the total floor area of the dining service for use per year; R.RVE(room revenue): the revenue generated from the accommodation service; D.REV(dining revenue): the revenue generated from the dining service; O.REV(other revenue): the revenue generated from other services excluding room and dining services. SL(share labor): number of employees in the managerial department that are responsible for administering both the accommodation and the dining services.

Table 4. Sorted ICs in terms of explained variability

\begin{tabular}{|c|c|c|c|c|c|c|}
\hline \multirow{3}{*}{ Year } & \multicolumn{2}{|c|}{ Service Production Input } & \multicolumn{2}{c|}{ Intermediate input/output } & \multicolumn{2}{c|}{ Service Operation Output } \\
\cline { 2 - 7 } & Number & Percentage & Number & Percentage & Number & Percentage \\
\hline \multirow{4}{*}{2009} & ICP1 & 30.00 & ICI1 & 60.35 & ICO1 & 37.05 \\
\cline { 2 - 7 } & ICP4 & 26.04 & ICI2 & 39.65 & ICO2 & 33.38 \\
\cline { 2 - 7 } & ICP3 & 25.10 & & & ICO3 & 29.57 \\
\cline { 2 - 7 } & $\%$ variability & 81.14 & & 100 & & 100 \\
\hline \multirow{4}{*}{2010} & ICP3 & 33.48 & ICI1 & 60.09 & ICO1 & 50.71 \\
\cline { 2 - 7 } & ICP1 & 30.05 & ICI2 & 39.91 & ICO2 & 44.70 \\
\cline { 2 - 7 } & ICP2 & 21.38 & & & & \\
\cline { 2 - 7 } & $\%$ variability & 84.91 & & 100 & & 95.41 \\
\hline \multirow{3}{*}{2011} & ICP4 & 37.93 & ICI1 & 5.52 & ICO1 & 45.26 \\
\cline { 2 - 7 } & ICP1 & 30.37 & ICI2 & 41.48 & ICO2 & 43.13 \\
\cline { 2 - 7 } & ICP2 & 19.47 & & & & 88.39 \\
\cline { 2 - 7 } & $\%$ variability & 87.77 & & 100 & & \\
\hline
\end{tabular}


End of Table 4

\begin{tabular}{|c|c|c|c|c|c|c|}
\hline \multirow{2}{*}{ Year } & \multicolumn{2}{|c|}{ Service Production Input } & \multicolumn{2}{|c|}{ Intermediate input/output } & \multicolumn{2}{|c|}{ Service Operation Output } \\
\hline & Number & Percentage & Number & Percentage & Number & Percentage \\
\hline \multirow{5}{*}{2012} & ICP2 & 28.32 & ICI2 & 57.70 & $\mathrm{ICO} 2$ & 63.30 \\
\hline & ICP3 & 22.46 & ICI1 & 42.30 & ICO1 & 18.41 \\
\hline & ICP5 & 20.06 & & & & \\
\hline & ICP1 & 17.80 & & & & \\
\hline & $\%$ variability & 88.64 & & 100 & & 81.71 \\
\hline \multirow{4}{*}{2013} & ICP1 & 31.91 & ICI2 & 57.70 & $\mathrm{ICO} 3$ & 50.80 \\
\hline & ICP3 & 29.86 & ICI1 & 42.30 & $\mathrm{ICO} 2$ & 29.17 \\
\hline & ICP2 & 19.66 & & & & \\
\hline & $\%$ variability & 81.43 & & 100 & & 79.97 \\
\hline \multirow{4}{*}{2014} & ICP3 & 49.47 & ICI2 & 80.65 & $\mathrm{ICO} 2$ & 68.65 \\
\hline & ICP1 & 28.47 & & & $\mathrm{ICO} 1$ & 19.28 \\
\hline & ICP4 & 9.63 & & & & \\
\hline & $\%$ variability & 87.57 & & 80.65 & & 87.93 \\
\hline \multirow{4}{*}{2015} & ICP3 & 52.18 & ICI1 & 72.96 & $\mathrm{ICO} 2$ & 49.88 \\
\hline & ICP2 & 23.12 & ICI2 & 27.04 & ICO3 & 28.65 \\
\hline & ICP4 & 10.65 & & & & \\
\hline & $\%$ variability & 85.95 & & 100 & & 78.53 \\
\hline
\end{tabular}

Table 5. The rank results of ICA-NSBM model for Taiwanese international tourist hotels

\begin{tabular}{|c|c|c|c|c|c|c|c|c|}
\hline DMU & 2009 & 2010 & 2011 & 2012 & 2013 & 2014 & 2015 & $2009-2015$ \\
\hline \multicolumn{7}{|c|}{ Managerial Performance } \\
\hline 28 & 1 & 1 & 1 & 1 & 1 & 1 & 1 & 1 \\
\hline 44 & 1 & 1 & 1 & 1 & 1 & 1 & - & 1 \\
\hline 51 & 1 & 1 & 1 & 1 & 1 & 1 & 1 & 1 \\
\hline 52 & - & - & - & - & - & - & 1 & 1 \\
\hline 63 & - & - & - & - & - & 1 & 30 & 5 \\
\hline 17 & 1 & 1 & 1 & 7 & 40 & 12 & 15 & 6 \\
\hline 14 & 7 & 14 & 37 & 10 & 14 & 9 & 27 & 7 \\
\hline 27 & 14 & 9 & 7 & 9 & 1 & 1 & 14 & 8 \\
\hline 13 & 12 & 1 & 1 & 13 & 13 & 17 & 9 & 9 \\
\hline 41 & 11 & 11 & 11 & 17 & 25 & 11 & 13 & 10 \\
\hline \hline 70 & - & - & 59 & 44 & 66 & 52 & 66 & 63 \\
\hline 46 & 46 & 55 & 61 & 65 & 57 & 45 & 50 & 64 \\
\hline 65 & 32 & 57 & 55 & 54 & 64 & 62 & 56 & 65 \\
\hline
\end{tabular}


Continue of Table 5

\begin{tabular}{|c|c|c|c|c|c|c|c|c|}
\hline DMU & 2009 & 2010 & 2011 & 2012 & 2013 & 2014 & 2015 & $2009-2015$ \\
\hline 9 & 42 & 48 & 60 & 64 & 59 & 40 & 64 & 66 \\
\hline 29 & 47 & 58 & 63 & 57 & 62 & 59 & 46 & 67 \\
\hline 48 & 39 & 56 & 58 & 58 & 63 & 55 & 67 & 68 \\
\hline 20 & 16 & 61 & 67 & 68 & 56 & 23 & 70 & 69 \\
\hline 1 & 49 & 21 & 66 & 67 & 68 & 65 & 69 & 70 \\
\hline 37 & 56 & 10 & 54 & 69 & 65 & 70 & 65 & 71 \\
\hline 24 & - & - & - & 53 & 70 & - & 71 & 72 \\
\hline \multicolumn{9}{|c|}{ Service Production } \\
\hline 28 & 1 & 1 & 1 & 1 & 1 & 1 & 1 & 1 \\
\hline 44 & 1 & 1 & 1 & 1 & 1 & 1 & - & 1 \\
\hline 51 & 1 & 1 & 1 & 1 & 1 & 1 & 1 & 1 \\
\hline 52 & - & - & - & - & - & - & 1 & 1 \\
\hline 17 & 1 & 1 & 1 & 1 & 1 & 19 & 1 & 5 \\
\hline 14 & 12 & 1 & 18 & 1 & 1 & 1 & 31 & 6 \\
\hline 27 & 28 & 1 & 1 & 16 & 1 & 1 & 21 & 7 \\
\hline 13 & 25 & 1 & 1 & 19 & 16 & 20 & 16 & 8 \\
\hline 43 & 19 & 1 & 19 & 22 & 1 & 1 & 29 & 9 \\
\hline 16 & 1 & 1 & 1 & 65 & 1 & 1 & 1 & 10 \\
\hline 71 & 55 & 41 & 44 & 45 & 46 & 49 & 45 & 63 \\
\hline 29 & 22 & 57 & 61 & 60 & 67 & 58 & 27 & 64 \\
\hline 23 & - & - & 66 & 32 & 28 & 47 & 71 & 65 \\
\hline 48 & 46 & 58 & 53 & 58 & 57 & 51 & 68 & 66 \\
\hline 65 & 24 & 59 & 58 & 54 & 62 & 67 & 43 & 67 \\
\hline 4 & 56 & 50 & 39 & 64 & 54 & 42 & 56 & 68 \\
\hline 70 & - & - & 60 & 47 & 66 & 44 & 69 & 69 \\
\hline 21 & 57 & 63 & 63 & 1 & 1 & 68 & 55 & 70 \\
\hline 30 & 51 & 62 & 67 & 1 & 65 & 70 & 1 & 71 \\
\hline 1 & 53 & 60 & 64 & 70 & 69 & 60 & 67 & 72 \\
\hline \multicolumn{9}{|c|}{ Service Operation } \\
\hline 28 & 1 & 1 & 1 & 1 & 1 & 1 & 1 & 1 \\
\hline 44 & 1 & 1 & 1 & 1 & 1 & 1 & - & 1 \\
\hline 51 & 1 & 1 & 1 & 1 & 1 & 1 & 1 & 1 \\
\hline 52 & - & - & - & - & - & - & 1 & 1 \\
\hline 63 & - & - & - & - & - & 1 & 1 & 1 \\
\hline 27 & 15 & 11 & 7 & 7 & 1 & 1 & 13 & 6 \\
\hline 14 & 1 & 18 & 48 & 15 & 18 & 10 & 22 & 7 \\
\hline 41 & 10 & 15 & 12 & 11 & 27 & 13 & 13 & 8 \\
\hline 17 & 1 & 1 & 1 & 11 & 54 & 12 & 19 & 9 \\
\hline 13 & 12 & 1 & 1 & 7 & 16 & 18 & 1 & 10 \\
\hline
\end{tabular}


End of Table 5

\begin{tabular}{|c|c|c|c|c|c|c|c|c|}
\hline DMU & 2009 & 2010 & 2011 & 2012 & 2013 & 2014 & 2015 & $2009-2015$ \\
\hline 29 & 51 & 56 & 59 & 52 & 52 & 53 & 54 & 63 \\
\hline 37 & 56 & 11 & 51 & 70 & 63 & 70 & 63 & 64 \\
\hline 60 & 54 & 48 & 49 & 61 & 56 & 60 & 56 & 65 \\
\hline 1 & 55 & 16 & 66 & 63 & 68 & 68 & 69 & 66 \\
\hline 19 & 31 & 57 & 62 & 65 & 62 & 34 & 66 & 67 \\
\hline 48 & 40 & 51 & 55 & 58 & 60 & 56 & 67 & 68 \\
\hline 46 & 52 & 60 & 61 & 67 & 64 & 64 & 48 & 69 \\
\hline 9 & 48 & 58 & 63 & 64 & 61 & 50 & 64 & 70 \\
\hline 20 & 13 & 62 & 67 & 68 & 66 & 30 & 70 & 71 \\
\hline 24 & - & - & - & 66 & 70 & - & 71 & 72 \\
\hline
\end{tabular}

Note: - represents that the hotel was not start the operation up or was excluded from the category of international tourist hotel.

\subsection{Comparison of the ICA-NSBM and NSBM models}

This paper aims to enhance the discriminatory power of two-stage NDEA-based evaluation framework under the presence of a high dimensionality of inputs/outputs. In order to demonstrate whether the ICA-NSBM model is valid, its discriminative performance is compared with that of the NSBM model, and the Wilcoxon signed-rank test, one of the best-known non-parametric methods, is applied for determining whether statistically significant differences exist between the results of two models (Zhang, 2001).

Table 6 is summarized the number of Taiwanese international tourist hotel with efficient score of 1 in the managerial performance and their two individual service-stage performances according to ICA-NSBM model and NSBM model. When the conventional NSBM model is executed, the number of efficient Taiwanese international tourist hotel varies from 12 to 20 in the managerial performance category. In contrast to the proposed ICA-NSBM model of used in this paper, the number of efficient Taiwanese international tourist hotel varies from 5 to 11 at the same performance category. There are fewer efficient Taiwanese international tourist hotel we can also observe obviously both in the service production performance and service operation categories. In other words, the proposed ICA-NSBM model can be treated as an effective performance evaluation model with more discriminatory power for identifying which hotel is better performer. The two-tailed Wilcoxon signed-rank test demonstrated in Table 7 shows that the ICA-NSBM model is significantly different from the NSBM model under the managerial performance category in 2009, 2014, and 2015. Overall, we thus conclude that the ICA-NSBM approach can efficiently enhance the discriminatory power of DEA-based performance model. 
Table 6. Number of efficient Taiwanese international tourist hotels from ICA-NSBM model and NSBM model

\begin{tabular}{|c|c|c|c|c|c|c|c|}
\hline \multirow{2}{*}{ Year } & \multirow{2}{*}{ Number } & \multicolumn{3}{|c|}{ NSBM model } & \multicolumn{3}{c|}{ ICA-NSBM model } \\
\cline { 3 - 8 } & & MPER & PE & OEV & MPER & PE & OEV \\
\hline 2009 & 57 & $14(24.56)$ & $22(38.60)$ & $15(26.32)$ & $5(8.77)$ & $11(19.30)$ & $6(10.53)$ \\
\hline 2010 & 63 & $19(30.16)$ & $23(36.51)$ & $19(30.16)$ & $7(11.11)$ & $26(41.27)$ & $9(14.29)$ \\
\hline 2011 & 68 & $19(27.94)$ & $23(33.82)$ & $21(30.88)$ & $6(8.82)$ & $17(25.00)$ & $6(8.82)$ \\
\hline 2012 & 70 & $18(25.71)$ & $29(41.43)$ & $18(25.71)$ & $6(8.57)$ & $14(20.00)$ & $6(8.57)$ \\
\hline 2013 & 70 & $16(22.86)$ & $24(34.29)$ & $17(24.29)$ & $11(15.71)$ & $15(21.43)$ & $13(18.57)$ \\
\hline 2014 & 70 & $20(28.57)$ & $33(47.14)$ & $20(28.57)$ & $8(11.43)$ & $17(24.29)$ & $8(11.43)$ \\
\hline 2015 & 71 & $12(16.90)$ & $29(40.85)$ & $16(22.86)$ & $6(8.45)$ & $12(16.90)$ & $12(16.90)$ \\
\hline
\end{tabular}

Note: MPER: the managerial performance; PE: the performance of service production stage; OEV: the performance of service operation stage. The parenthesis gives the percentage of efficient performer.

Table 7. Wilcoxon signed-rank test between ICA-NSBM model and NSBM model

\begin{tabular}{|l|c|c|c|c|c|c|c|}
\hline & 2009 & 2010 & 2011 & 2012 & 2013 & 2014 & 2015 \\
\hline NSBM & 0.737 & 0.723 & 0.733 & 0.757 & 0.733 & 0.762 & 0.722 \\
\hline ICA-NSBM & 0.549 & 0.750 & 0.715 & 0.731 & 0.709 & 0.709 & 0.803 \\
\hline Z-value $^{*}$ & -5.645 & -0.887 & -0.214 & -0.030 & -0.830 & -1.854 & -3.238 \\
\hline (P-Value) $^{(0.000)}$ & $(0.375)$ & $(0.831)$ & $(0.976)$ & $(0.406)$ & $(0.064)$ & $(0.001)$ \\
\hline
\end{tabular}

Note: *: NSBM model > ICA-NSBM model.

\subsection{Managerial decision matrix}

Based on the comparison analysis of performance evaluation between the proposed ICANSBM model and NSBM model, we have demonstrated the discriminatory ability of the former in the international tourist hotel industry in Taiwan. Obviously, the performance in the service production stage is significantly better than that in the service operation stage. Figure 2 presented a managerial decision matrix that combined service production efficiency (PE) with service operation effectiveness (OEV), to further locate and rank the managerial performance of international tourist hotels in Taiwan over the period 2009-2015, based on the proposed ICA-NABM model. The table classified each hotel into a quadrant in terms of two criteria: (1) whether the average performance score of the service production stage is more or less than the mean score of the service production stage (0.8768) and (2) whether the average performance score of the service operation stage is more or less than the mean score of the service operation stage (0.5927). The smaller the score the less competitiveness a hotel is in terms of service production or service operation and vice versa. Overall, the results of managerial decision matrix revealed that international tourist hotels in Taiwan, on average, performed well in service production. The DMU should modify long-term operating 


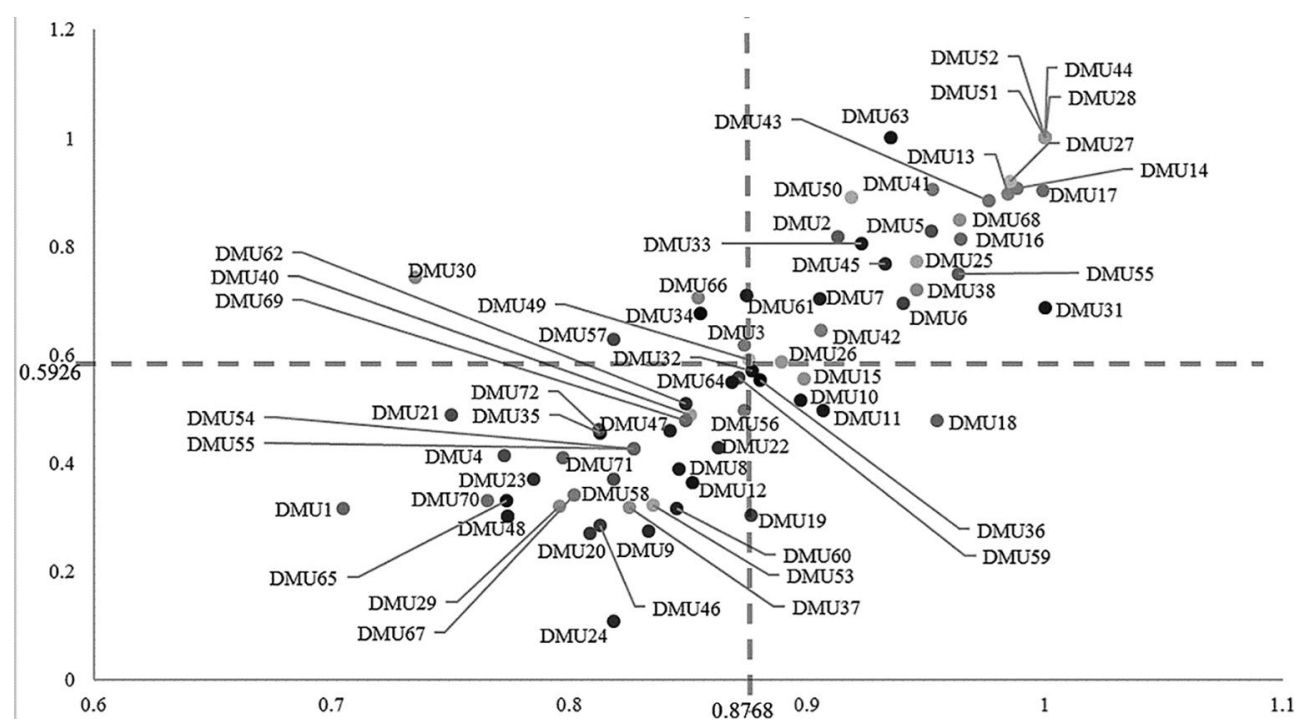

Figure 2. Managerial decision matrix based on the average score of the managerial performance over 7-year (2009-2015)

planning on service operation to enhance their competitiveness. The results indicated that all the sampled hotels fell into one of the following four quadrants:

- Hotels with a competitive advantage in terms of both service production performance and service operation performance: Twenty-five international tourist hotels have relatively excellent service production and service operation performances. Only four hotels (e.g., DMU28, DMU44, DMU51, and DMU52) would be seen as benchmarks for others, especially in which is located in this category. These DMUs should maintain their competitive advantages and pursue all avenues to discover the sources of inefficiency.

- Hotels with competitive advantages in terms of service operation performance. Seven international hotels have a competitive advantage in terms of the service operation stage, but they are weak in terms of the service production stage. Hotel managers need to assess inefficient factors, such as redundant personnel, to improve service production performance and maintain a secure competitive advantage in terms of service operation performance.

- Hotels with competitive advantages in terms of service production performance. Seven international hotels have relatively high service production performance, but low service operation performance. This might imply service wastefulness compared with capacity. Thus, there is a need for hotel managers here to explore new marketing opportunities for generating services revenue.

- Hotels with low service production and service operation performance. These thirty-three hotels are the poorest performers in terms of service production and service operation in the Taiwanese international tourist hotels. They should thus adopt strategies to increase overall performance, such as expanding customer services to improve the service operation stage and executing cost control measures to increase 
services production. DMU1, for example, has been ranked as a poor performer on the average performance scores in both the service production and operation stages over the period 2009 to 2015 . It was a result of inefficient performance in its room department: as most of its profit came from dining service, it still spent a great deal on infrastructure and operating expense for the continuation of room/bed services.

\section{Conclusions}

The international tourist hotels are deemed as an important industry in Taiwan for providing economic contribution. With the deregulation of tourist from mainland China in 2008, competition for lodger as the operational desire by international tourist hotels to increase their profitability is a crucially managerial question. This is important to introduce a performance model with better discriminatory power to hotels' manager or government who is very concerned about identifying the inefficient sources to improve operational outcome and industrial environment under a severe competition. There are numerously previous studies focusing on the performance model construction in a specific year. In this study, we enrich the literature by proposing a modified two-stage NDEA performance model with ICA technique to measure the managerial performance of Taiwanese international tourist hotels over the period 2009-2015. In the proposed ICA-NSBM model, we first adopted a NSBM model with two-stage framework, the managerial performance is composed of the performance of service production and service operation. Secondly, the concept of maximum variance explanation is used to reduce the dimensionality of the selected variables of NSBM model, representing that the original input, intermediate, and output variables were replaced by the selected ICs. Finally, the chosen ICs were fed into a NSBM model in computing the managerial performance scores of Taiwanese international tourist hotels. At the same time, the performance of service production and service operation stages is also obtained from the managerial performance. This empirical evaluation has the following three findings. First, the worse performance of service operation will hamper the managerial performance, and it is one of the most significant questions of hotels manager and government to find a solution to that problem urgently. Second, the proposed ICA-NSBM model has better discriminatory power than the conventional NSBM model under the presence of high-dimensional variables.

\section{References}

Adler, N., \& Golany, B. (2001). Evaluation of deregulation airline networks using data envelopment analysis combined with principle component analysis with an application to Western Europe. European Journal of Operational Research, 132(6), 18-31.

Adler, N., \& Golany, B. (2002). Including principle component weights to improve discrimination in data envelopment analysis. Journal of the Operational Research Society, 53(9), 985-991.

https://doi.org/10.1057/palgrave.jors.2601400

Adler, N., \& Yazhemsky, E. (2010). Improving discrimination in data envelopment analysis: PCA-DEA or variable reduction. European Journal of Operational Research, 202(1), 273-284.

https://doi.org/10.1016/j.ejor.2009.03.050 
Afsharinia, A., Bagherpour, M., \& Farahmand, K. (2013). Efficiency measurement of clinical units using integrated independent component analysis-DEA model under Fuzzy conditions. International Journal of Hospital Research, 2(3), 109-118.

Assaf, A., \& Barros, C. (2011). Performance analysis of the Gulf hotel industry: a Malmquist index with bias correction. International Journal of Hospitality Management, 30(4), 819-826. https://doi.org/10.1016/j.ijhm.2011.01.002

Avkiran, N. K. (2009). Opening the black box of efficiency analysis: an illustration with UAE banks. Omega-International Journal of Management Science, 37(4), 930-941. https://doi.org/10.1016/j.omega.2008.08.001

Back, A. D., \& Weigend, A. S. (1997). A first application of independent component analysis to extracting structure from stock returns. International Journal of Neural Systems, 8(4): 473-484. https://doi.org/10.1142/S0129065797000458

Ban, O. I., Tara, I. G., Bogdan, V., Tuşe, D., \& Bologa, S. G. (2016). Evaluation of hotel quality attribute importance through fuzzy correlation coefficient. Technological and Economic Development of Economy, 22(4), 471-492. https://doi.org/10.3846/20294913.2016.1144657

Barros, C. P., Managi, S., \& Matousek, R. (2012). The technical efficiency of the Japanese banks: nonradial directional performance measurement with undesirable output. Omega-International Journal of Management Science, 40(1), 1-8. https://doi.org/10.1016/j.omega.2011.02.005

Bian, Y. (2012). A Gram-Schmidt process based approach for improving DEA discrimination in the presence of large dimensionality of data set. Expert Systems with Applications, 39(3), 3793-3799. https://doi.org/10.1016/j.eswa.2011.09.080

Castelli, L., Pesenti, R., \& Ukovich, W. (2010). A classification of DEA models when the international structure of the Decision Making Units in considered. Annals of Operations Research, 173(1), 207235. https://doi.org/10.1007/s10479-008-0414-2

Chen, T. H. (2009). Performance measurement of an enterprise and business units with an application to a Taiwanese hotel chain. International Journal of Hospitality Management, 28(3), 415-422. https://doi.org/10.1016/j.ijhm.2008.10.010

Färe, R., \& Grosskopf, S. (2000). Network DEA. Socio-Economic Planning Science, 34(1), 35-49. https://doi.org/10.1016/S0038-0121(99)00012-9

Galagedera, D. U. A., Watson, J., Premachandra, I. M., \& Chen, Y. (2016). Modelling leakage in twostage DEA models: an application to US mutual fund families. Omega-International Journal of Management Science, 61, 62-77. https://doi.org/10.1016/j.omega.2015.07.007

García-Ferrer, A., González-Prieto, E., \& Peña, D. (2012). A conditionally heteroskedastic independent factor model with an application to financial stock returns. International Journal of Forecasting, 28(1), 70-93. https://doi.org/10.1016/j.ijforecast.2011.02.010

Hadad, Y., Friedman, L., \& Israeli, A. A. (2005). Evaluating hotel advertisements efficiency using data envelopment analysis. Journal of Business Economics and Management, 6(3), 145-153.

Hsieh, L. F., \& Lin, L. H. (2010). A performance evaluation model for international tourist hotels in Taiwan - an application of the rational network DEA. International Journal of Hospitality Management, 29(1), 14-24. https://doi.org/10.1016/j.ijhm.2009.04.004

Hu, J. L., Chiu, C. N., Shieh, H. S., \& Huang, C. H. (2010). A stochastic cost efficiency analysis of international tourist hotels in Taiwan. International Journal of Hospitality Management, 29(1), 99-107. https://doi.org/10.1016/j.ijhm.2009.06.005

Huang, C. W. (2018). Assessing the performance of tourism supply chains by using the hybrid network data envelopment analysis model. Tourism Management, 65, 303-316.

https://doi.org/10.1016/j.tourman.2017.10.013 
Huang, C. W., Ho, F. N., \& Chiu, Y. H. (2014). Measurement of tourist hotels' productive efficiency, occupancy, and catering service effectiveness using a modified two-stage DEA model in Taiwan. Omega-The International Journal of Management Science, 48, 49-59. https://doi.org/10.1016/j.omega.2014.02.005

Hwang, S. N., \& Chang, T. Y. (2003). Using data envelopment analysis to measure hotel managerial efficiency change in Taiwan. Tourism Management, 24(4), 357-369. https://doi.org/10.1016/S0261-5177(02)00112-7

Hyvärinen, A., Karhunen, J., \& Oja, E. (2001). Independent component analysis. New York: John Wiley \& Sons. https://doi.org/10.1002/0471221317

Hyvärinen, A., \& Oja, E. (2000). Independent component analysis: algorithms and applications. Neural Networks, 13(4-5), 411-430. https://doi.org/10.1016/S0893-6080(00)00026-5

Jenkins, L., \& Anderson, M. (2003). A multivariate statistical approach to reducing the number of variables in data envelopment analysis. European Journal of Operational Research, 147(1), 51-61. https://doi.org/10.1016/S0377-2217(02)00243-6

Kao, H. Y., Wu, D. J., \& Huang, C. H. (2017). Evaluation of cloud service industry with dynamic and network DEA models. Applied Mathematics and Computation, 315, 188-202. https://doi.org/10.1016/j.amc.2017.07.059

Kao, L. J., Lu, C. J., \& Chiu, C. C. (2011). Efficiency measurement using independent component analysis and data envelopment analysis. European Journal of Operational Research, 210(2), 310-317. https://doi.org/10.1016/j.ejor.2010.09.016

Lewis, H. F., \& Sexton, T. R. (2004). Network DEA: efficiency analysis of organizations with complex internal structure. Computers \& Operations Research, 31(9), 1365-1410. https://doi.org/10.1016/S0305-0548(03)00095-9

Liang, L., Li, Y., \& Li, S. (2009). Increasing the discriminatory power of DEA in the presence of the undesirable outputs and large dimensionality of data sets with PCA. Expert Systems with Applications, 36(3), 5895-5899. https://doi.org/10.1016/j.eswa.2008.07.022

Lin, T. Y., \& Chiu, S. H. (2013). Using independent component analysis and network DEA to improve bank performance evaluation. Economic Modelling, 32(5), 608-616. https://doi.org/10.1016/j.econmod.2013.03.003

Mahlberg, B., \& Sahoo, B. K. (2011). Radial and non-radial decomposition of Luenberger productivity indicator with an illustrative application. International Journal of Production Economics, 131(2), 721-726. https://doi.org/10.1016/j.ijpe.2011.02.021

Marchetti, D., \& Wanke, P. (2017). Brazil's rail freight transport: efficiency analysis using two-stage DEA and cluster-driven public policies. Socio-Economic Planning Sciences, 59, 26-42. https://doi.org/10.1016/j.seps.2016.10.005

Nataraja, N. R., \& Johnson, A. L. (2011). Guidelines for using variable selection techniques in data envelopment analysis. European Journal of Operational Research, 215(3), 662-669. https://doi.org/10.1016/j.ejor.2011.06.045

National Development Council (NDC). (2016). Taiwan macro-economic insight 2016. Retrieved from http://www.ey.gov.tw/state/News_Content3.aspx?n=3F00F60B9FC304D7\&s=2FE35E5B857F7A92

Oukil, A., Channouf, N., \& AL-Zaidi, A. (2016). Performance evaluation of the hotel industry in an emerging tourism destination: the case of Oman. Journal of Hospitality and Tourism Management, 29, 60-68. https://doi.org/10.1016/j.jhtm.2016.05.003

Seiford, L. M., \& Zhu, J. (1999). Profitability and marketability of the top 55 US commercial banks. Management Science, 45(9), 1270-1288. https://doi.org/10.1287/mnsc.45.9.1270

Taiwan Tourism Bureau. (2017). Tourism Statistics Database. Retrieved from http://admin.taiwan.net. tw/statistics/year_en.aspx?no=15 
Tone, K., \& Tsutsui, M. (2009). Network DEA: a slacks-based measure approach. European Journal of Operational Research, 197(1), 243-252. https://doi.org/10.1016/j.ejor.2008.05.027

Vaz, C. B., Camanho, A. S., \& Guimarães, R. C. (2010). The assessment of retailing efficiency using network data envelopment analysis. Annals of Operations Research, 173(1), 5-24. https://doi.org/10.1007/s10479-008-0397-z

Xu, X., \& Cui. Q. (2017). Evaluating airline energy efficiency: an integrated approach with Network Epsilon-based Measure and Network Slacks-based Measure. Energy, 122, 274-286. https://doi.org/10.1016/j.energy.2017.01.100

Yang, C., \& Liu, H. M. (2012). Managerial efficiency in Taiwan bank branches: a network DEA. Economic Modelling, 29(2), 450-461. https://doi.org/10.1016/j.econmod.2011.12.004

Yang, Z., Xia, L., \& Cheng, Z. (2017). Performance of Chinese hotel segment markets: efficiencies measure based on both endogenous and exogenous factors. Journal of Hospitality and Tourism Management, 32, 12-23. https://doi.org/10.1016/j.jhtm.2017.04.007

Yu, M. M. (2010). Assessment of airport performance using the SBM-NDEA model. Omega-International Journal of Management Science, 38(6), 440-452. https://doi.org/10.1016/j.omega.2009.11.003

Yu, M. M., \& Lee, C. Y. (2009). Efficiency and effectiveness of service business: evidence from international tourist hotels in Taiwan. Tourism Management, 30(4), 571-580. https://doi.org/10.1016/j.tourman.2008.09.005

Yu, M. M., \& Lin, T. J. (2008). Efficiency and effectiveness in railway performance using a multi-activity network DEA model. Omega-International Journal of Management Science, 36(6), 1005-1017. https://doi.org/10.1016/j.omega.2007.06.003

Zha, Y., Liang, N., Wu, M., \& Bian, Y. (2016). Efficiency evaluation of banks in China: a dynamic twostage slacks-based measure approach. Omega-The International Journal of Management Science, 60, 60-72. https://doi.org/10.1016/j.omega.2014.12.008

Zhang, G. P. (2001). An investigation of neural networks for linear time-series forecasting. Computers \& Operations Research, 28(12), 1183-1202. https://doi.org/10.1016/S0305-0548(00)00033-2 